\title{
Cytotoxicity of Oxycodone and Morphine in Human Neuroblastoma and Mouse Motoneuronal Cells: A Comparative Approach
}

\author{
Merja Kokki $^{1,2} \cdot$ Maija Pesonen $^{3} \cdot$ Piia Vehviläinen $^{4} \cdot$ Outi Litmala $^{1,2,3}$ • \\ Markku Pasanen ${ }^{3}$ - Hannu Kokki ${ }^{1,2}$
}

Published online: 25 February 2016

(c) The Author(s) 2016. This article is published with open access at Springerlink.com

\begin{abstract}
Background and Objectives Oxycodone is the most commonly used opioid for the treatment of moderate to severe pain. The peak cerebrospinal fluid concentration after epidural oxycodone was reported to be 300 -fold greater $(0.025 \mathrm{mM})$ than when administered intravenously after gynecologic surgery. Additionally, those patients administered epidural oxycodone had lower pain scores, needed less rescue analgesics and had fewer adverse effects compared with intravenous administration. However, oxycodone neurotoxicity requires evaluation before intrathecal implementation for routine clinical use.
\end{abstract}

This study is part of the KuBiCo (Kuopio Birth Control) consortium (www.KuBiCo.fi) for Merja Kokki, Markku Pasanen and Hannu Kokki.

Some of the results of this study were presented as an abstract at the Euroanaesthesia 2015 congress held in Berlin, Germany, from 30 May-2 June 2015.

Hannu Kokki

hannu.kokki@uef.fi

1 Anaesthesiology and Intensive Care Medicine, School of Medicine, University of Eastern Finland, Kuopio, Finland

2 Department of Anesthesia and Operative Services, Kuopio University Hospital, PO Box 100, 70029 KYS Kuopio, Finland

3 School of Pharmacy, University of Eastern Finland, Kuopio, Finland

4 Department of Neurobiology, A.I. Virtanen Institute, University of Eastern Finland, Kuopio, Finland
Methods We used two in vitro cell culture models to compare the cytotoxicity of oxycodone with that of morphine, and to study the mechanisms underlying toxicity. Human neuroblastoma cells and mouse motoneuronal cells were treated with increasing concentrations (0.0125-2 mM) of oxycodone or morphine, and were harvested at 24,48 or $96 \mathrm{~h}$. Cell cultures were evaluated with 3-(4,5-dimethylthiazole-2-yl)-2,5-diphenyltetrazolium bromide and resazurin reduction assays.

Results Both morphine and oxycodone decreased cell viability in a dose-dependent manner at concentrations between 0.5 and $2 \mathrm{mM}$. Morphine increased the number of apoptotic cells compared with oxycodone when assessed by flow cytometry, and transmission electron microscopy images revealed that exposure to both opioids evoked the appearance of numerous electron-dense, probable autophagic vacuoles in the cytoplasm of the cells.

Conclusions Based on these results, it seems that the cytotoxicity of oxycodone in motoneuronal cells is similar to or less than that of morphine, and occurs only at concentrations above the peak clinical concentration in the cerebrospinal fluid after epidural administration. 


\section{Key Points}

Opioids are needed for the management of severe pain, and intrathecal administration is the most effective route for opioid analgesia; however, neurotoxicity is a concern in spinal and epidural administration of medicines.

The use of oxycodone has surpassed that of morphine, and preliminary data suggest that epidural oxycodone can be highly effective and welltolerated; however, the safety and efficacy of intrathecal oxycodone has not been established.

We have evaluated the neurotoxicity of oxycodone in two commonly used cell models. The data indicate that the neurotoxicity of oxycodone is similar to that of morphine, which is a gold standard for intrathecal opioid administration.

\section{Introduction}

Oxycodone is a semi-synthetic opioid agonist derived from thebaine. It is increasingly used for the treatment of moderate to severe pain. Over the last decade, oxycodone use has surpassed that of morphine, and the global consumption of oxycodone is almost twofold higher than that of morphine; in 2012 the global consumption of oxycodone amounted 82,049 $\mathrm{kg}$ compared with a global consumption of $45,641 \mathrm{~kg}$ of morphine [1]. Oxycodone is often administered intravenously or subcutaneously and, as it has a relatively high oral bioavailability of between 40 and $65 \%$, administration by mouth is used in patients with normal gastrointestinal function.

Opioid receptors are mainly distributed in the central nervous system and spinal cord, and thus most of the actions of opioid agonists arise from these sites. Since 1976, when Yaksh and Rudy demonstrated the direct analgesic action of opioids on the spinal cord, there has been growing interest to use intrathecal opioids in the management of severe pain [2].

Few studies have evaluated the neuraxial administration of oxycodone with conflicting results of efficacy [3-5]. Two earlier studies reported only slight amplification in analgesic efficacy of epidural oxycodone compared with intravenous administration [3, 4]; however, in our recent study of women having lower abdominal surgery, a high analgesic efficacy of epidural oxycodone was demonstrated. Patients who were administered segmental epidural oxycodone had less pain and needed less rescue pain medication compared with intravenous administration and, in this small sample, epidural oxycodone was well-tolerated. In addition, spinal pharmacokinetics were in favor of epidural administration, and the cerebrospinal fluid peak molar concentration $(0.025 \mathrm{mM})$ after epidural oxycodone was 300 -fold greater than when administered intravenously [5].

However, to the best of our knowledge, neurotoxicity of intrathecal oxycodone has not been established; neurotoxicity requires evaluation before implementation of intrathecal oxycodone to routine clinical practice. To gain further knowledge of the potential toxicity at cellular level, the effects of oxycodone and morphine on cell viability and ultrastructure, as well as on markers of oxidative stress and cell cycle arrest in human (SH-SY5Y) and mouse (NSC34) motoneuronal cells, were investigated in vitro.

\section{Materials and Methods}

\subsection{Chemicals}

3-(4,5-Dimethylthiazole-2-yl)-2,5-diphenyltetrazolium bromide (MTT), propidium iodide (PI), resazurin sodium salt and RNA-ase were obtained from Sigma-Aldrich (Helsinki, Finland); oxycodone and morphine were both purchased from Leiras Takeda Oy (Helsinki, Finland); Dulbecco's modified Eagle medium (DMEM), fetal bovine serum (FBS), and gentamicin were obtained from Lonza (Verviers, Belgium); anti-p21WAF1/Cip1 (12D1) antibodies, anti- $\beta$-actin, and anti-rabbit-immunoglobulin (Ig) G were provided by Cell Signaling Technology (Danvers, MA, USA); anti-heme oxygenase antibodies were obtained from Santa Cruz Biotechnology, Inc. (Santa Cruz, CA, USA); $\mathrm{ECL}^{\mathrm{TM}}$ prime Western blotting reagents and anti-mouse $\mathrm{IgG}$ horseradish peroxidase (HRP)-labeled antibody were provided by Amersham BioSciences (Buckinghamshire, UK); polyvinylidene difluoride (PVDF) membranes were provided by Millipore Laboratories, Inc. (Espoo, Finland); and the $10 \mathrm{~mm}$ culture plates were obtained from Sarstedt Inc. (Newton, MA, USA) and the 48-well plates were obtained from Nunc A/S (Roskilde, Denmark).

\subsection{Cell Culture and Treatment}

Human neuroblastoma cells (SH-SY5Y) were obtained from the European Collection of Animal Cell Cultures (Salisbury, UK). The cells were maintained in DMEM supplemented with heat-inactivated FBS $(9 \%)$ and gentamicin $(10 \mu \mathrm{g} / \mathrm{ml})$ at $37{ }^{\circ} \mathrm{C}$ in a $5 \% \mathrm{CO}_{2} 95 \%$ air-humidified incubator. In the experiments, the cells were seeded at densities that allowed the untreated cells to reach 
a nearly confluent state at the end of the experiments. The cells were treated with increasing concentrations of oxycodone or morphine after $48 \mathrm{~h}$ of plating in fresh medium and were harvested at 24,48 or $96 \mathrm{~h}$ after treatment. Oxycodone and morphine were diluted in culture medium, and the medium was changed every second day.

Mouse motoneuronal cells, NSC-34 (kindly provided by Prof. Jari Koistinaho, A.I. Virtanen Institute, University of Eastern Finland) [6], were cultured in DMEM supplemented with $10 \%$ FBS as well as $100 \mathrm{U} / \mathrm{ml}$ penicillin and $100 \mu \mathrm{g} / \mathrm{ml}$ streptomycin at $37{ }^{\circ} \mathrm{C}$ in a $5 \% \mathrm{CO}_{2} 95 \%$ airhumidified incubator.

\subsection{Cell Viability}

The viability of the cultured SH-SY5Y cells was determined by the MTT reduction assay described previously by Pesonen et al. [7] In brief, the cells were seeded in 48-well plates $\left(4-5 \times 10^{4} /\right.$ well $)$ and exposed to various concentrations $(0.0125-2 \mathrm{mM})$ of oxycodone or morphine for $48 \mathrm{~h}$. After exposure, the medium was changed to an MTTcontaining $(0.5 \mathrm{mg} / \mathrm{ml})$ medium and the incubation continued at $37^{\circ} \mathrm{C}$ for $2 \mathrm{~h}$. Thereafter, the medium was removed and formazan crystals that had formed were solubilized with SDS-HCl buffer ( $\mathrm{pH}$ 4.7). Absorbance was measured at $570 \mathrm{~nm}$ using an $\mathrm{EL}_{\mathrm{x}} 800$ plate reader (Biotek Instruments Inc., Winooski, VT, USA).

The viability of NSC-34 cells was determined by the resazurin reduction assay and was carried out with four replicates. Resazurin is a non-toxic and non-fluorescent blue reagent that is reduced to fluorescent and pink-colored resorufin by viable cells. Briefly, the cells were incubated with $10 \mu \mathrm{M}$ resazurin diluted in culture medium at $37{ }^{\circ} \mathrm{C}$ for $2 \mathrm{~h}$. The absorbance was measured at $590 \mathrm{~nm}$ (Wallac Victor2 1420 Multilabel Counter; PerkinElmer, MA, USA)

\subsection{Flow Cytometric Analysis}

Flow cytometric analysis after PI staining was performed as previously described by Nuutinen et al. [8]. Briefly, the SH-SY5Y cells were trypsinized and collected together with detached cells from the medium, and centrifuged at $1500 \mathrm{rpm}$ for $5 \mathrm{~min}$. The pellet was resuspended in phosphate-buffered saline (PBS) and fixed with ethanol $(70 \%)$ at $+4{ }^{\circ} \mathrm{C}$ for $24 \mathrm{~h}$. Thereafter, the cells were centrifuged at $1600 \mathrm{rpm}$ and ethanol was decanted and the pellet resuspended in PBS containing RNA-ase $(0.15 \mathrm{mg} /$ $\mathrm{ml}$ ), and incubated at $+50{ }^{\circ} \mathrm{C}$ for $1 \mathrm{~h}$. The cells were then centrifuged and the pellet resuspended in PBS containing PI $(8 \mu \mathrm{g} / \mathrm{ml})$ and incubated $+37{ }^{\circ} \mathrm{C}$ for $2 \mathrm{~h}$. The stained cells were analyzed by FACS Canto II equipment (BDFACSDiva, version 6.1.3; BD Biosciences, San Jose, CA, USA).

\subsection{Transmission Electron Microscopy}

After exposure, the cells were fixed with $25 \mathrm{mg} / \mathrm{ml}$ glutaraldehyde in phosphate buffer ( $\mathrm{pH} 7.4)$, and post-fixed in $10 \mathrm{mg} / \mathrm{ml}$ osmium tetraoxide $\left(\mathrm{OsO}_{4}\right)$ for $3 \mathrm{~h}$. The cells were then dehydrated with increasing concentrations of ethanol and embedded in Epon LX-112 resin (Ladd Research Industries Inc., Williston, VT, USA). The blocks were sectioned into ultrathin slices and double stained with uranyl acetate and lead citrate. The samples were examined with a transmission electron microscope (JEM-2100F; Jeol Ltd, Tokyo, Japan).

\subsection{Electrophoresis and Immunoblotting Analysis}

Immunoblotting was carried out using the whole-cell proteins. In isolation of the protein fractions, the cells were washed with ice-cold PBS and scraped from the plates (on ice) in cold PBS, centrifuged at $1300 \mathrm{rpm}$ for $10 \mathrm{~min}$, and the pellets suspended in radioimmunoprecipitation assay (RIPA)-like lysis-buffer $(50 \mathrm{mM}$ Tris-HCl, $\mathrm{pH} 7.4$, $250 \mathrm{mM} \mathrm{NaCl}, 0.1 \%$ SDS, $0.5 \%$ NP40, $2 \mathrm{mM}$ dithiothreitol, and protease and phosphatase inhibitors). The suspensions were incubated on ice for $30 \mathrm{~min}$ and centrifuged at $13,000 \mathrm{rpm}$ for $15 \mathrm{~min}$. Supernatants were collected and used for analysis. Protein concentrations of the fractions were measured with the Bradford method using protein assay reagent obtained from BioRad Laboratories Inc. (Philadelphia, PA, USA).

The cell protein fractions were subjected to $100-150 \mathrm{mg} / \mathrm{ml}$ sodium dodecyl sulphate-polyacrylamide gel electrophoresis and transferred to PVDF membranes, as described previously [9]. p21 protein was analyzed using anti-p21 antibodies (1:1000) and heme oxygenase-1 (HO1) anti-heme oxygenase (1:500) as primary antibodies, and anti-rabbit or anti-mouse antibodies as the secondary antibodies (1:2000). Densitometric analysis of protein bands was carried out using the QuantityOne ${ }^{\circledR}$ program (BioRad Laboratories Inc., Hercules, CA, USA), and the data were normalized by $\beta$-actin, which was used as the loading control. The Western blot analysis was carried out from three independently performed cell exposure experiments.

\subsection{Statistics}

Results obtained using SH-SY5Y cells are expressed as the mean (standard deviation) or a percentage of the control cells, as appropriate. For $\mathrm{EC}_{50}$ values, $95 \%$ confidence intervals (CI) were calculated. Six independent experiments with SH-SY5Y cells containing six replicates per concentration were performed, and the overall significance between groups and concentrations was calculated using a 
linear mixed effect model. Group differences were tested using an independent samples $t$ test in different concentration points. To calculate $\mathrm{EC}_{50}$ for both compounds, concentrations were $\log 10$-transformed, and analyzed by non-linear regression analysis using the following equation:

$y=\operatorname{minimum}+\frac{\text { maximum }- \text { minimum }}{1+10^{(\operatorname{LogEC} 50-x) * \text { hillslope }}}$

using a constraint of $y=0$ for the minimum. Non-linear curves were fitted for exposures and controls separately, and Student's $t$ test was used to compare $\log \mathrm{EC}_{50}$ parameters. Statistical analysis were performed using IBM SPSS Statistics for Windows version 22.0. (IBM Corporation, Armonk, NY, USA), and non-linear regression analysis was performed using R version 3.1.1 for Windows (R Foundation for Statistical Computing, Vienna, Austria). A $p$ value $<0.05$ was considered as significant.

\section{Results}

Both morphine and oxycodone decreased SH-SY5Y cell viability in a dose-dependent manner, as analyzed by the MTT assay. A statistically significant decrease was seen using a $0.5 \mathrm{mM}$ concentration of both opioids, and the $\mathrm{EC}_{50}$ was similar in the two groups- $-0.82 \mathrm{mM}(95 \%$ CI $0.78-0.87)$ for morphine and $0.81 \mathrm{mM}(95 \%$ CI $0.78-0.85)$ for oxycodone ( $p=0.7, n=6$. However, significant difference was noted between the two compounds $(p=0.015)$ as cell viability was significantly less with morphine with the two highest concentrations $(1.5 \mathrm{mM}, p<0.001$; and $2 \mathrm{mM}, p=0.018$ ) than with oxycodone (Fig. 1).

Microscopy of the cells after oxycodone treatments revealed cytoplasmic vacuoles at higher concentrations

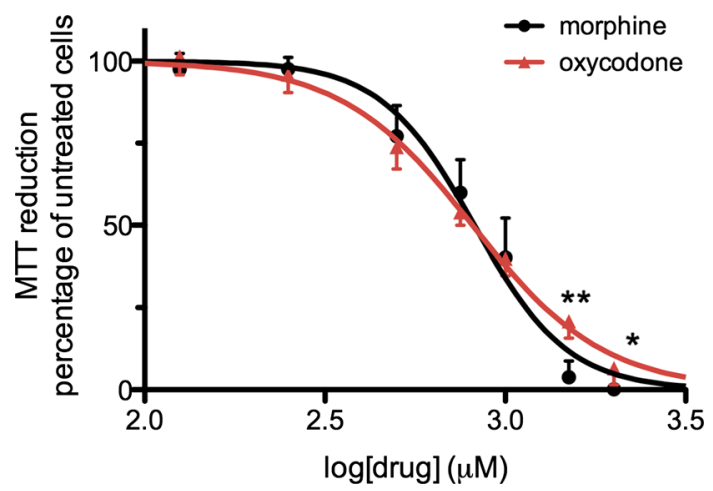

Fig. 1 The effect of morphine and oxycodone on SH-SY5Y cell viability. The cells were exposed to various concentrations of oxycodone or morphine, and cell viability was determined by MTT assay and expressed as a percentage of untreated cells. * Indicates $p=0.018$ and $* *$ indicates $p<0.001$ between the two groups. MTT 3-(4,5-dimethylthiazole-2-yl)-2,5-diphenyltetrazolium bromide
(1-2 mM), whereas the highest concentration (2 $\mathrm{mM})$ of morphine caused de-attachment of the cells and massive cell death (Fig. 2). Similar cytoplasmic vacuoles and cell death were not seen in the control cultures. Transmission electron microscopy of SH-SY5Y cells showed appearance of many electron-dense vacuoles that contained cytoplasmic material such as ribosomes and degradation products after oxycodone exposure (Fig. 3a). These vacuoles resemble autophagosome/lysosome structures and were observable at $0.5-1 \mathrm{mM}$ concentrations of oxycodone. Only a few similar vacuoles were seen after exposure to the same concentrations of morphine. Instead, several swollen mitochondria were seen, indicating mitochondria damage by morphine exposure $(0.25-1 \mathrm{mM})$ (Fig. 3b). The highest concentration of oxycodone or morphine $(2 \mathrm{mM})$ increased a number of empty (electron-lucent) vacuoles, suggesting fluid accumulation into the cells and membrane disturbances (Fig. 3b, d).

To study whether cytotoxicity would be associated with apoptosis or cell cycle arrest, control and opioid-treated SH-SY5Y cells were analyzed using flow cytometer after PI staining (Table 1). Exposure of the cells to morphine (0.5-2 mM) increased the number of sub-G1-phase cells representing apoptotic cells from $3 \%$ up to $50 \%$, whereas the increase of apoptotic cells by the same concentrations of oxycodone was less, i.e. from $3 \%$ up to $13 \%$. In control cultures, approximately $2 \%$ of the cells were in the sub-G1 phase, and approximately $69 \%$ in the G1/G0 phase.

Next, the expression of markers for cell cycle arrest (p21 protein [10]) and oxidative stress (HO1 [11]), was evaluated by immunoblotting after exposure of SH-SY5Y cells to various concentrations of oxycodone or morphine (Fig. 4). Both opioids increased the amount of p21 protein in a dosedependent manner over the control levels at 24 and $48 \mathrm{~h}$ of exposure. The highest increase by oxycodone was approximately fourfold over the control level, whereas the highest increase by morphine was approximately tenfold over the control level. The other marker protein, HO1, showed weak increase only at lower concentrations of oxycodone $(0.25-0.5 \mathrm{mM})$ after $48 \mathrm{~h}$ of exposure (data not shown).

Mouse motoneuronal cells, NSC-34, show a similar sensitivity to both morphine- and oxycodone-induced toxicity than human neuroblastoma cells on the resazurin reduction assay. Only the highest concentrations $(2 \mathrm{mM})-$ and no concentrations of $0.25 \mathrm{mM}$ or lower-clearly decreased NSC-34 cell viability after 96 h of treatment.

\section{Discussion}

Neuraxial opioids are highly effective analgesics due to direct uptake into the spinal cord and cerebrospinal fluid [5]. In neuraxial analgesia, safety is an issue as medicines 

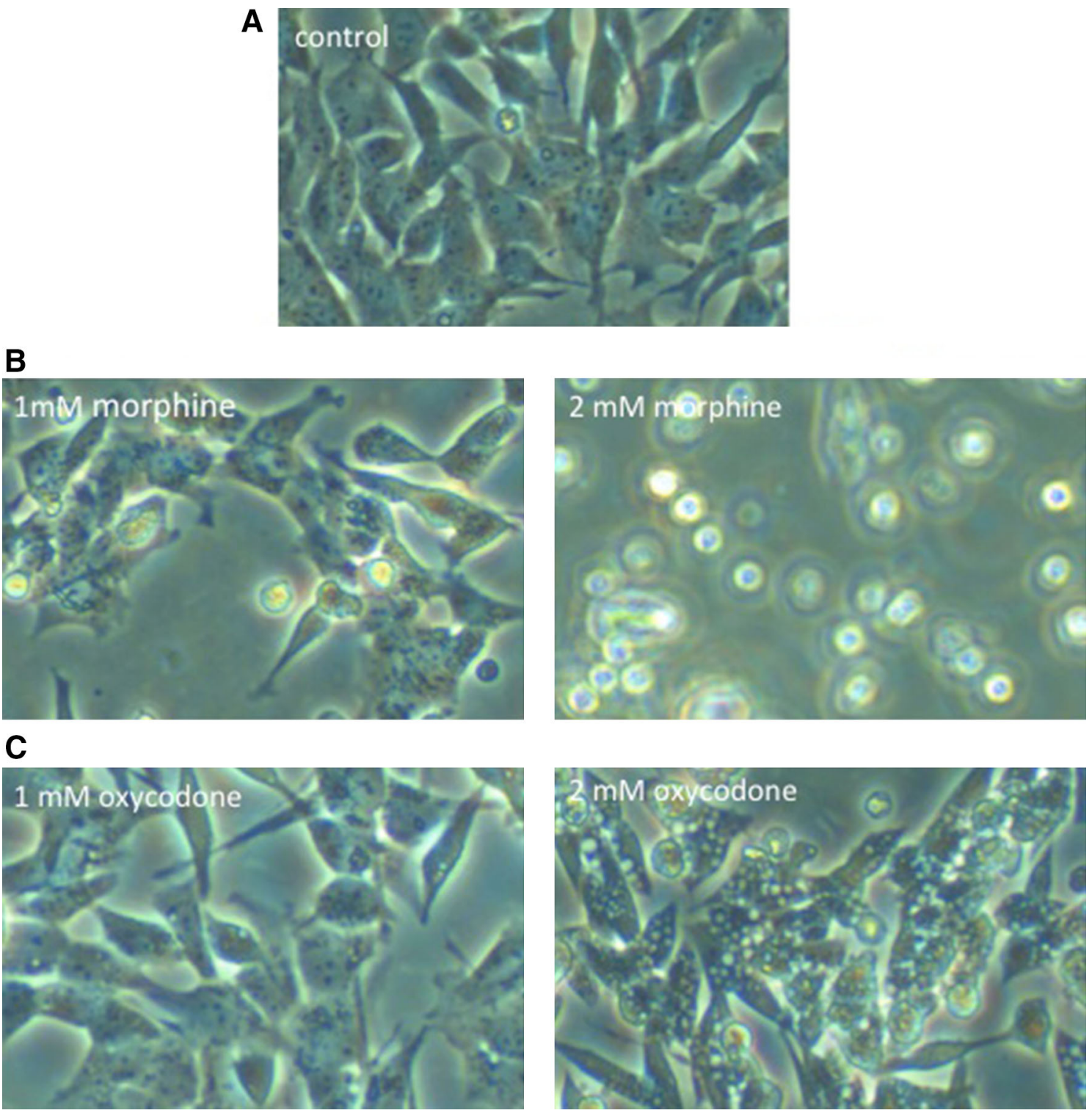

Fig. 2 Light microscopy of untreated and opioid-treated SH-SY5Y cells. a Untreated SH-SY5Y cells; b cells treated with various concentrations of morphine ( 1 and $2 \mathrm{mM})$; and c cells treated with various concentrations of oxycodone $(1$ and $2 \mathrm{mM})$. Magnification $\times 100$

are administered into a close proximate of neural structures, and thus screening for potential neurotoxicity should be performed for all compounds intended for epidural or spinal administration [12]. Since its first neuraxial application in the late 1970s, morphine has been the gold standard for spinally administered opioids, and morphine is one of two opioids, along with sufentanil, that has been approved for intrathecal delivery in most countries [13]; however, this does not imply or rule out that morphine is an ideal drug for neuraxial administration. The highest concern with intraspinal morphine is the risk of both early and delayed respiratory depression after cephalad spread in the cerebrospinal fluid [14]. Other opioids are also administered intrathecally, although many of them, like fentanyl, are neither approved for intrathecal administration nor formally evaluated for neurotoxicity; however, extensive clinical experience with fentanyl is used to ensure the safety of intrathecal administration [15].

Oxycodone is structurally related to morphine, and our hypothesis was that cytotoxicity of oxycodone should be similar to that of morphine, and this was the case. Based on the data, the neurotoxic potential between morphine and oxycodone in vitro with two cell lines of neurological origin are well comparable. However, based on the effects on mitochondria toxicity, a signal that occurred at the lowest concentration, and cell cycle arrest potency, morphine proved to be slightly more potent than oxycodone. The safety factor for morphine after a single administration 

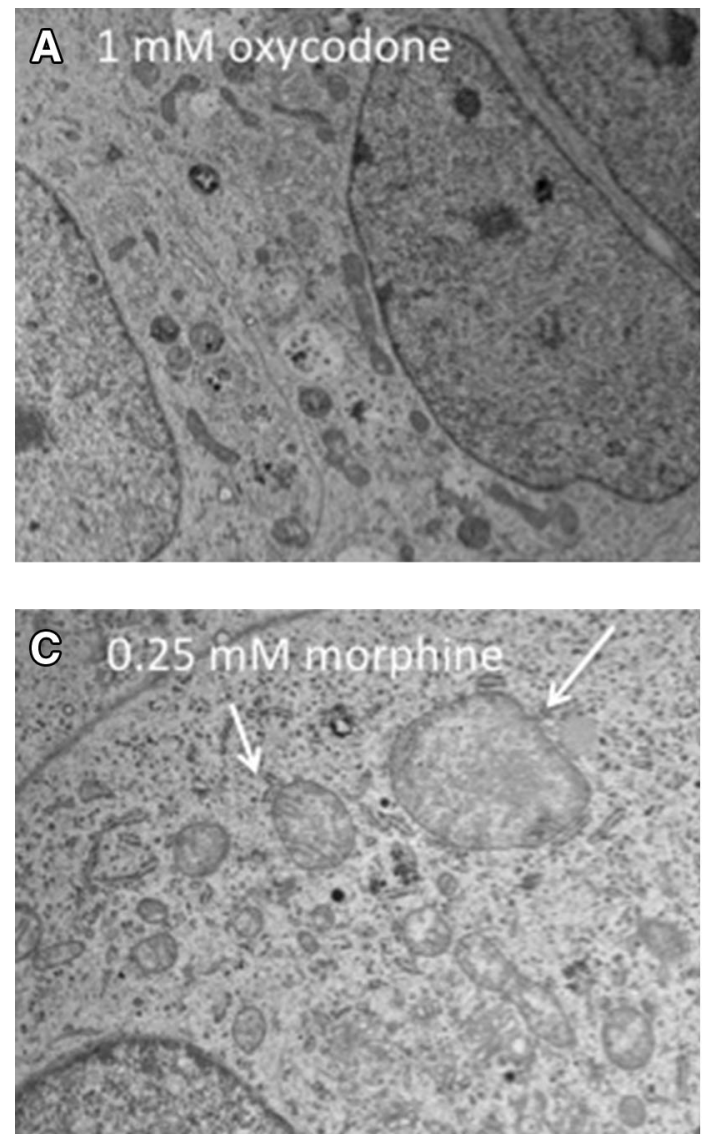

Fig. 3 Transmission electron micrographs of SH-SY5Y cells. a Cells treated with oxycodone $(1 \mathrm{mM})$ for $24 \mathrm{~h}$. A number of autophagosome-lysosome vacuoles can be seen in the cytoplasm of the cells; mitochondria are intact (magnification $\times 2000)$. b Cells treated with oxycodone ( $2 \mathrm{mM})$. Empty, electron-lucent vacuoles are seen in the
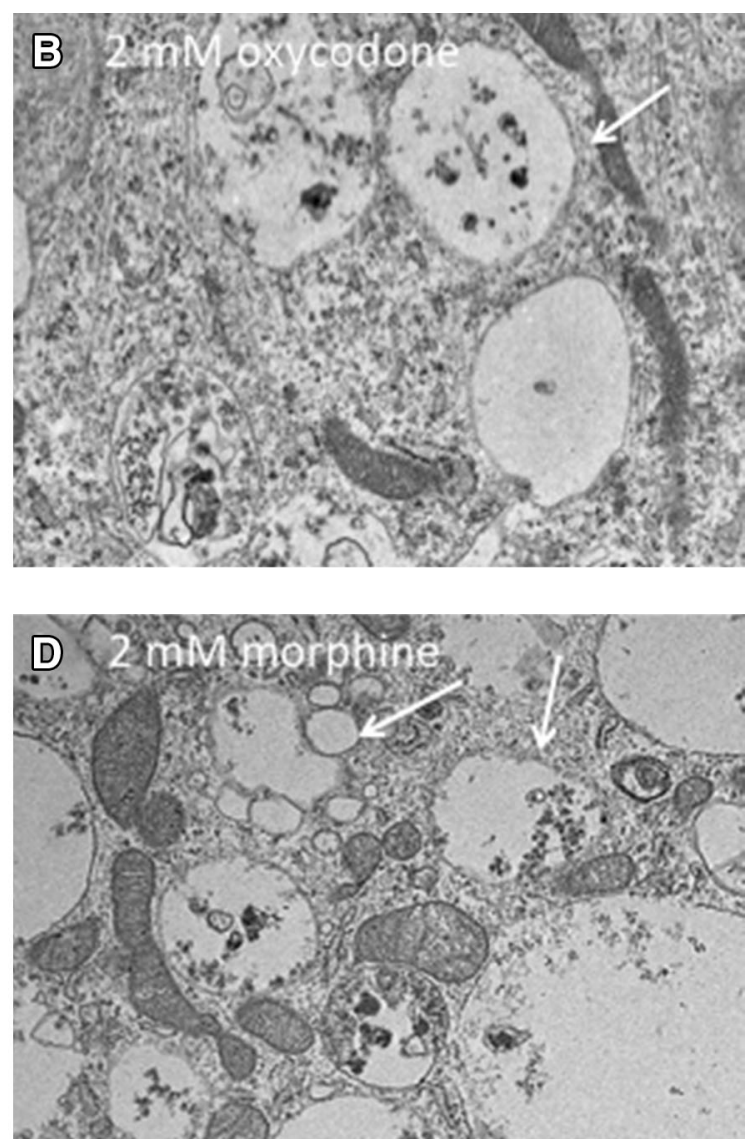

cytoplasm. c Swollen mitochondria in the cytoplasm of cells treated with morphine $(0.25 \mathrm{mM})$. d Increasing empty vacuoles in the cytoplasm of SH-SY5Ycells treated with morphine $(2 \mathrm{mM})$. Magnification $\times 5000$
Table 1 The effect of morphine or oxycodone on the cell cycle of neuroblastoma cells $^{\mathrm{a}}$

\begin{tabular}{|c|c|c|c|c|c|c|c|}
\hline \multirow[t]{2}{*}{ Cell phase } & \multirow[t]{2}{*}{ Control } & \multicolumn{3}{|c|}{ Morphine $[\mathrm{mM}]$} & \multicolumn{3}{|c|}{ Oxycodone [mM] } \\
\hline & & 0.5 & 1 & 2 & 0.5 & 1 & 2 \\
\hline SubG1 & $2.1(1.2)$ & $3.4(1.2)$ & $13.7(0.2)$ & $50.1(6.7)$ & $3.1(0.4)$ & $5.7(1.1)$ & $13.8(4.5)$ \\
\hline G1/G0 & $69.8(4.8)$ & $74.2(1.3)$ & $74.9(1.8)$ & $29.7(0.3)$ & $70.1(2.4)$ & $75.3(6.0)$ & $73.0(3.9)$ \\
\hline S & $11.6(3.1)$ & $9.2(0.9)$ & $5.0(0.6)$ & $8.4(3.0)$ & $10.1(1.0)$ & $8.3(2.9)$ & $6.1(0.6)$ \\
\hline $\mathrm{G} 2 / \mathrm{M}$ & $15.9(3.5)$ & $12.8(4.0)$ & $6.3(1.8)$ & $9.5(5.3)$ & $15.9(1.0)$ & $10.6(1.9)$ & $7.0(1.5)$ \\
\hline
\end{tabular}

Data are expressed as mean (standard deviation) from two or three independent experiments

a The cells were exposed for $24 \mathrm{~h}$, stained with propidium iodide and analyzed with flow cytometry for mitochondrial damage is 10 if $0.025 \mathrm{mM}$ [5] peak clinical concentration is the reference value, suggesting that, at the concentrations commonly used in clinical practice, the risk for neurotoxicity is low. Based on the data, morphine-induced neurotoxicity could be linked to mitochondria-mediated apoptotic processes, which could be anchored with the increased expression of the p53 and p21 proteins and cell cycle arrest. The differences in neurotoxic potential between morphine and oxycodone may also be catalyzed by different additional mechanisms of actions that cannot be identified by the limited set of tests used in the study. However, cytotoxic reactions were identified for both compounds only at concentrations far above the peak clinical concentration $(0.025 \mathrm{mM})$ in the cerebrospinal fluid after epidural administration [5], and therefore may not be a cause of concern in acute administrations; however, after repeated administration, these signals should be considered. 


\section{A Oxycodone}

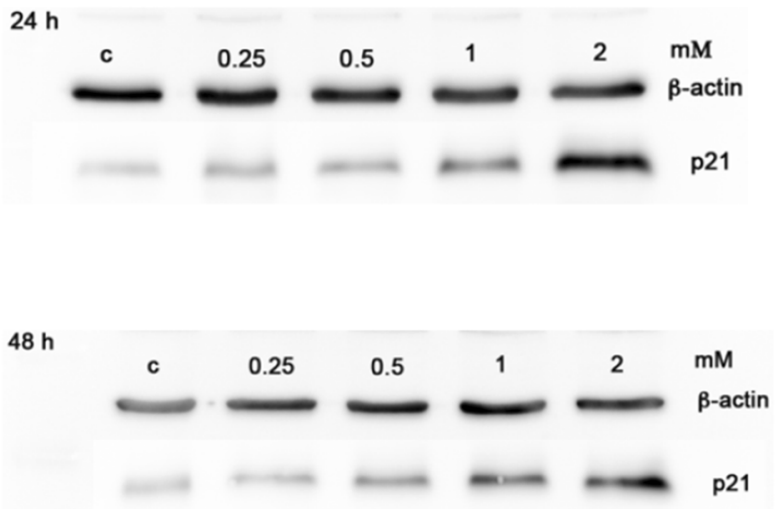

\section{B Morphine}
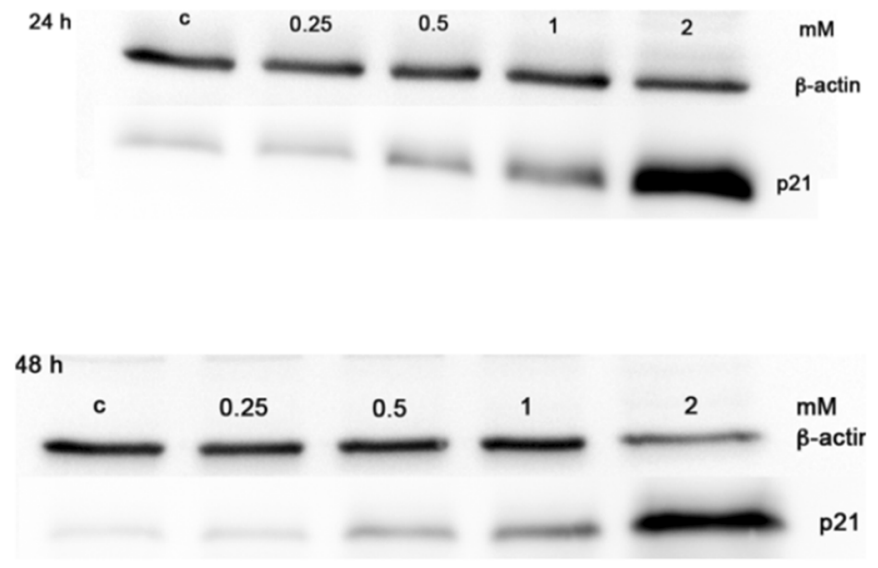
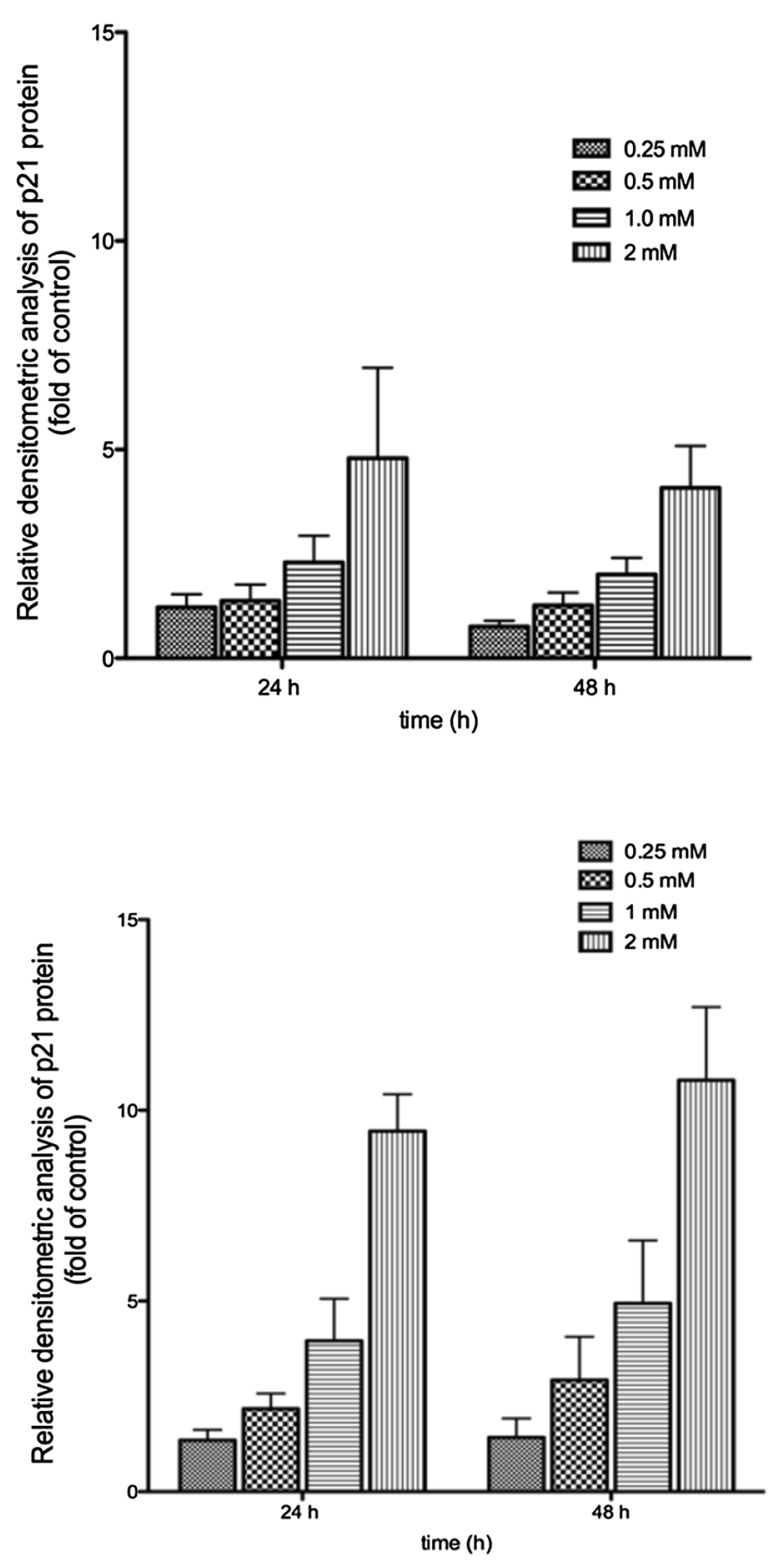

fold increase relative to the control values, and each column represents the mean (standard deviation) from three independent experiments $(\mathrm{c}=\mathrm{control})$. Representative immunoblot and densitometrically analyzed columns of p21 protein after exposure of SHSY5Ycells to various concentrations of $\mathbf{a}$ oxycodone and $\mathbf{b}$ morphine

epidural injection of $0.1 \mathrm{mg} / \mathrm{kg}$ body weight is $0.007 \mathrm{mM}$ [16]. Thus, we concluded that the oxycodone and morphine concentrations evaluated in this study were appropriate and a certain safety margin for clinical use of oxycodone and morphine has been identified.

In this study, we used a human neuroblastoma cell line that is a neuronal-like cell line, and mouse motoneuron cell line, in order to have an anatomically relevant cell line for comparison. The toxicity of both compounds appeared to be similar in both cell lines. Cell toxicity of oxycodone has 
also been evaluated in human hepatoma HepG2 cells. Incubation of HepG2 cells with an oxycodone concentration of $0.2 \mathrm{mM}$ did not indicate loss of cell viability, depletion of glutathione or decreased total protein count, which might reflect higher protective metabolic capacity of hepatocytes compared with neural cells [17]. Genotoxicity of oxycodone has been evaluated in the Ames Salmonella typhimurium and Escherichia coli test, chromosomal aberration test in human lymphocytes, and the in vivo bone marrow micronucleus test in mice, indicating no mutagenic for oxycodone. Oxycodone has only been shown to be clastogenic in concentrations considerably higher than the clinical dose range. Clastogenicity has been detected in the presence of metabolic activation in the human chromosomal aberration test at $3 \mathrm{mM}$ of exposure, and in the mouse lymphoma assay at doses of $0.125 \mathrm{mM}$ or greater with metabolic activation and $1 \mathrm{mM}$ or greater without metabolic activation. Some gene mutation has been detected in an in vitro mammalian cell test at $1 \mathrm{mM}$. Neither developmental nor reproductive toxicity has been found in rats and rabbits [18].

Recent data indicate that the spinal pharmacokinetics and pharmacodynamics of oxycodone are in favor of epidural administration compared with intravenous administration [5]; however, further studies are needed to demonstrate the clinical safety of neuraxial oxycodone, and multiple models should be applied to assess neurotoxicity. Exposure of cell cultures may reveal potential toxicity, and can be useful for sorting out the possible mechanisms of toxicity of compounds. Exposing cell lines to naloxone would be interesting in evaluating whether the neurotoxicity is opioid receptor-related or not; however, data relating to morphine indicate that opioid receptor-related mechanisms may not be involved [19]. In addition, spinal cord or nerve root toxicity may also manifest itself as histologic, physiologic, or behavioral/clinical derangements. Experimental data in rats indicate that after intrathecal injection, opioid-induced hyperalgesia may last for 1-2 days [12, 20]. Ideally, a complete roster of histological, physiologic, and behavioral testing would be performed on spinal drugs in two or more animal species, followed by safety trials in humans prior to widespread clinical use [21].

In further studies, the safety of oxycodone local anesthetic combinations should also be evaluated. Intrathecal opioids are commonly used in combination with local anesthetics and vice versa to improve the analgesic effectiveness of neuraxial analgesia and also to reduce the requirement of single compounds. Contrary to opioids, local anesthetics are neurotoxic at subclinical concentrations, which has been demonstrated with neuronal cells $[22,23]$ and has also been found in clinical practice [24]. These studies are clinically paramount because epidural analgesia using local anesthetics with an opioid are highly effective and improve patient outcome compared with patients receiving systemic, standard-care analgesia [25].

\section{Conclusions}

Data indicate that the cytotoxic potential of oxycodone in human (SHSY5Y) and mouse (NSC-34) neuroblastoma spinal cord cells is similar or less than that of morphine, and occurs only at concentrations far above the peak clinical concentration in the cerebrospinal fluid after epidural administration of both compounds.

\section{Compliance with Ethical Standards}

Funding This study was funded by the governmental VTR fund, the Hospital District of Northern Savo, Kuopio, Finland.

Conflicts of interest Merja Kokki, Maija Pesonen, Piia Vehviläinen, Outi Litmala, Markku Pasanen and Hannu Kokki have no conflicts of interest to declare.

Open Access This article is distributed under the terms of the Creative Commons Attribution-NonCommercial 4.0 International License (http://creativecommons.org/licenses/by-nc/4.0/), which permits any noncommercial use, distribution, and reproduction in any medium, provided you give appropriate credit to the original author(s) and the source, provide a link to the Creative Commons license, and indicate if changes were made.

\section{References}

1. International Narcotics Control Board, United Nations. INCB annual report 2014. Available at: https://www.incb.org/ documents/Narcotic-Drugs/Technical-Publications/2014/ND_ TR_2014_4_Tables_EFS.pdf. Accessed 10 Sept 2015.

2. Yaksh TL, Rudy TA. Analgesia mediated by a direct spinal action of narcotics. Science. 1976;192:1357-8.

3. Bäcklund M, Lindgren L, Kajimoto Y, Rosenberg PH. Comparison of epidural morphine and oxycodone for pain after abdominal surgery. J Clin Anesth. 1997;9:30-5.

4. Yanagidate F, Dohi S. Epidural oxycodone or morphine following gynaecological surgery. Br J Anaesth. 2004;93:362-7.

5. Kokki M, Välitalo P, Kuusisto M, et al. Central nervous system penetration of oxycodone after intravenous and epidural administration. Br J Anaesth. 2014;112:133-40.

6. Cashman NR, Durham HD, Blusztajn JK, et al. Neuroblastoma $\times$ spinal cord (NSC) hybrid cell lines resemble developing motor neurons. Dev Dyn. 1992;194:209-21.

7. Pesonen M, Pasanen M, Loikkanen J, et al. Chloropicrin induces endoplasmic reticulum stress in human pigment epithelial cell. Toxicol Lett. 2012;211:39-45.

8. Nuutinen U, Postila V, Mättö M, et al. Inhibition of P13-kinaseAkt pathway enhances dexamethasome-induced apoptosis in a human follicular lymphoma cell line. Exp Cell Res. 2006;312:322-30.

9. Tampio M, Loikkanen J, Myllynen P, Mertanen A, Vähäkangas $\mathrm{KH}$. Benzo(a)pyrene increases phosphorylation of p53 at serine 392 in relation to p53 induction and cell death in MCF-7. Toxicol Lett. 2008;178:152-9. 
10. Dutto I, Tillhon M, Cazzalini O, Stivala LA, Prosperi E. Biology of the cell cycle inhibitor $\mathrm{p} 21^{\mathrm{CDKN} 1 \mathrm{~A}}$ : molecular mechanisms and relevance in chemical toxicology. Arch Toxicol. 2015;89:155-78.

11. Ryter SW, Choi AM. Heme oxygenase-1: molecular mechanisms of gene expression in oxygen-related stress. Antioxid Redox Signal. 2002;4:625-32.

12. Eisenach JC, James FM 3rd, Gordh T Jr, Yaksh TL. New epidural drugs: primum non nocere. Anesth Analg. 1998;87:1211-2.

13. Wang JK, Nauss LA, Thomas JE. Pain relief by intrathecally applied morphine in man. Anesthesiology. 1979;50:149-51.

14. Wheatley RG, Schug SA, Watson D. Safety and efficacy of postoperative epidural analgesia. Br J Anaesth. 2001;87:47-61.

15. Hodgson PS, Neal JM, Pollock JE, Liu SS. The neurotoxicity of drugs given intrathecally (spinal). Anesth Analg. 1999;88:797-809.

16. Drost RH, Ionescu TI, Taverne RH, van Lingen G, van Rossum JM, Maes RA. Pharmacokinetics of morphine in cerebrospinal fluid and plasma after epidural administration in man. Arzneimittelforschung. 1988;38:1632-4.

17. Jairaj M, Watson DG, Grant MH, Skellern GG. The toxicity of opiates and their metabolites in HepG2 cells. Chem Biol Interact. 2003;146:121-9.

18. Physicians Desk Reference. 69th ed. Montvale: PDR Network, LCC; 2014. p. 2128.
19. Lin $\mathrm{X}$, Wang YJ, Li Q, Hou YY, Hong MH, Cao YL, et al. Chronic high-dose morphine treatment promotes SH-SY5Y cell apoptosis via c-Jun N-terminal kinase-mediated activation of mitochondria-dependent pathway. FEBS J. 2009;276:2022-36.

20. Célèrier E, Rivat C, Jun Y, Laulin JP, Larcher A, Reynier P, et al. Long-lasting hyperalgesia induced by fentanyl in rats: preventive effect of ketamine. Anesthesiology. 2000;92:465-72.

21. Van Elstraete AC, Sitbon P, Trabold F, Mazoit JX, Benhamou D. A single dose of intrathecal morphine in rats induces long-lasting hyperalgesia: the protective effect of prior administration of ketamine. Anesth Analg. 2005;101:1750-6.

22. Perez-Castro R, Patel S, Garavito-Aguilar ZV, et al. Cytotoxicity of local anesthetics in human neuronal cells. Anesth Analg. 2009;108:997-1007.

23. Werdehausen R, Fazeli S, Braun S, et al. Apoptosis induction by different local anaesthetics in a neuroblastoma cell line. $\mathrm{Br} \mathrm{J}$ Anaesth. 2009;103:711-8.

24. Rigler ML, Drasner K, Krejcie TC, et al. Cauda equina syndrome after continuous spinal anesthesia. Anesth Analg. 1991;72:275-81.

25. Pöpping DM, Elia N, Van Aken HK, et al. Impact of epidural analgesia on mortality and morbidity after surgery: systematic review and meta-analysis of randomized controlled trials. Ann Surg. 2014;259:1056-67. 